During the whole course of the case the pulse remained very constant at about 80 , except for a moment at times when some excitement occurred. Under such circumstances it was once noticed at 100 , but immediately subsided to its former condition. On Thursday afternoon, a few hours before death, it rose to 112 , and probably increased to the end. She died at midnight after an illness of four days. Neither pouring of water from one vessel to another, nor the flashing of light upon glass, nor the sight of water (unless she was asked to swallow it) ever brought on the spasms. In looking back upon the symptoms in this case, I cannot avoid asking myself the question, Why did this patient die? Taking away the peculiar symptoms which made it hydrophobia, I think no physician would for a moment have felt any anxiety about the case.

Indeed, without the local convulsions produced by the attempt to swallow liquids there would have been no case, and the prognosis given by Dr. Green at a consultation on Wednesday afternoon, when the question of recovery was broached, is about all that can be said upon the subject, namely, "It is hydrophobia, and therefore she must die."

It is greatly to be regretted that we know so little of the disease, and it will be to the everlasting disgrace of the Massachusetts Medical Society if, with the constant recurrence of cases at the present day, effectual means are not taken to systematize the knowledge we really have, and thoroughly to investigate the subject.

\title{
A CONTRIBUTION TO THE STATISTICS OF GYNACCOLOGY.
}

BY VIRGIL O. HARDON, M. D.,

Physician to the Out-Patient Department of the Rhode 1sland Hospital, and Physician to the Providence Dispensary.

DURING the past year my attention has often been directed to the frequency of the occurrence of laceration of the cervix uteri in parous women, and to the infrequency of the recognition of this condition by the majority of physicians. I therefore took pains during the three months of my last term of service as physician to the out-patient department of the Rhode Island Hospital to preserve notes of all the cases of uterine disease which came under my observation and treatment. As a result I offer the following statistics:-

Whole number of cases treated, twenty-seven. Of these, five occurred in nulliparous and twenty-two in parous women. In the five nulliparous women no laceration was found, of course. Of the twentytwo parous women, nineteen had laceration of the cervix to such an extent as to lead to eversion of the lips and apparent ulceration, and to produce symptoms of sufficient severity to cause the patient to apply 
for treatment. These symptoms consisted in every case of leucorrhœal discharge, pain in the back and side, especially after walking, bearing down or dragging sensations about the loins, irritation of the bladder, shown by frequent micturition, in fourteen of the cases severe, continuous headache at the vertex of the head, extending back to the occiput, and in five cases gastric irritation, which was relieved as soon as the severity of the uterine symptoms was ameliorated by treatment.

The youngest patient was seventeen years old, the eldest forty-two, and the remainder of the cases were pretty evenly distributed between these two ages.

Ten of the cases had been treated for "ulcers on the womb," but in no case had there been any permanent relief from the distressing symptoms. These are the statements of the patients, and must of course be taken with a certain degree of allowance.

Seven of the cases were complicated 'by anteflexion, three by retroflexion, and one by polypus of the cervical canal. The remaining eight appeared to be uncomplicated, except by a considerable amount of endocervicitis and congestion of the cervix, which existed to a greater or less degree in every one of the cases. In every case there was the so-called ulceration taking its starting-point from the angle of the laceration covering nearly or quite the whole of the everted surfaces.

Of the nineteen patients, eight had borne but one child, while eleven had borne more than one, the greatest number being seven. In fourteen, miscarriage had occurred at some previous time.

Nine referred the beginning of their symptoms to a previous miscarriage, six to a confinement at term, and four were unable to trace any such causation. Of the six who dated their trouble from a confinement, two described their labors as long ones, one being of seventy-four and the other of fifty-eight hours' duration. The third was delivered by forceps after being in labor about nine hours. The remaining three described their labors as quick and easy ones.

In eight of the cases laceration occurred upon both sides of the cervix, in nine upon the left side alone, and in only two upon the right side alone. In every case there was evidence of previous cellulitis in the form of tenderness, thickening of the broad ligaments, and plastic deposit in the roof of the pelvis. In eleven cases the evidences of cellulitis existed upon both sides, and in eight cases only upon the left side. It is a noticeable fact that when the cellulitis had existed only upon one side it was invariably the left side. At a meeting of the New York Obstetrical Society, Professor Peaslee ${ }^{1}$ referred to this fact, and gave as a reason "the return of the venous blood by the spermatic or ovarian vein proper, and not directly into the ascending vena cava by a short vein, as on the right side, whereby a venous stagnation and hyperæmia might

1 American Journal of Obstetrics, October, 1876. 
be more readily induced, and a cellulitis of the left side brought about." Dwight ${ }^{3}$ has confirmed this theory by anatomical demonstration, and has shown that a varicose condition of the veins of the pelvic region may exist upon the left side while the right side remains perfectly normal. He considers this condition as analogous to varicocele in the male, and suggests that many of the cases of so-called cellulitis may be simply varicocele of the broad ligament and neighboring structures.

These cases still remain under treatment, and I hope at some future time to be able to give the results. Suffice it to say that the copious vaginal douche of hot water forms the chief element of the first stage of treatment preparatory to the operation devised by Emmet ${ }^{2}$ for the restoration of the lacerated cervix to its normal condition. An appreciable relief of all the symptoms is visible in from one to two weeks after the use of the vaginal douche is commenced. To this rule $I$ have found no exception.

In every case the examination was made with a Sims's speculum with the patient in Sims's position, for I believe that the diagnosis of laceration of the cervix is impossible except under these conditions.

As far as so small a number of cases can be considered as proving anything, these statistics go to show :-

(1.) That laceration of the cervix to an extent sufficient to produce troublesome symptoms is a very frequent condition in women who have borne children.

(2.) That this condition may generally be referred to a miscarriage or to a labor at term as a cause, and that it may result from an easy labor as well as from a long or a hard one.

(3.) That as a rule extensive laceration of the cervix leads to pelvic cellulitis, and that both the laceration and the resulting cellulitis are very much more likely to occur upon the left than upon the right side.

\section{RECENT PROGRESS IN OPHTHALMOLOGY. ${ }^{8}$}

BY O. F. WADSWORTH, M. D.

Therapeutic Effect of Tattooing the Cornea. - Warning has been given, by several writers, against the wounding of vessels in tattooing the cornea as likely to interfere with the effect. Voelkers' experience, however, led him to a contrary opinion. He observed in cases tattooed for the opacities due to recurrent keratitis that the recurrence was stopped by the tattooing. In these cases the vessels on the cornea had been pricked and the coloring matter (India ink) had appeared to enter and fill the vessels; he concluded, therefore, that the disposition to fresh

\footnotetext{
1 Boston Medical and Surgical Journal, February 15, 1877.

2 Americen Journal of Obstetrics, Norember, 1874.

8 Concluded from page 581 .
} 